\title{
Attention deficit hyperactivity disorder in Australia: Perspectives from the sociology of deviance
}

Journal of Sociology 20I5, Vol. 5I(3) 596-6I2 (C) The Author(s) 2014

Reprints and permissions: sagepub.co.uk/journalsPermissions.nav DOI: $10.1177 /|4407833| 35 \mid 4643$ jos.sagepub.com

@SAGE

\section{Brenton Prosser}

Australian National University, Australia

\begin{abstract}
Over the last twenty years, attention deficit hyperactivity disorder (ADHD) has become one of the most diagnosed childhood disorders in the western world. Research within the disciplines of psychiatry and criminology has increasingly identified a link between ADHD, delinquency and crime. So far, consideration of ADHD from sociological perspectives has been limited, while it has been virtually ignored as a diagnosis with social impact and a popular phenomenon within Australia. In response, this article draws on conceptual resources from the sociology of deviance to illustrate the value of sociological perspectives and to explore questions about the impact of ADHD that psycho-medical perspectives cannot. In doing so, the article adds to existing understandings of the social aspects of this prominent disorder and aims to encourage the development of new conceptualisations that lie beyond the existing deficit label.
\end{abstract}

\section{Keywords}

attention deficit hyperactivity disorder, criminology, medicalisation, popular culture, social problems

\section{ADHD: a diagnosis with impact}

The Diagnostic and Statistical Manual of Mental Disorders (DSM) (American Psychiatric Association, 2000) defines attention deficit hyperactivity disorder (ADHD) as a biological dysfunction that results in hyperactive, inattentive and impulsive behaviour to such an extent that it causes problems in home, school and work settings. ${ }^{1}$ Typically, ADHD

\section{Corresponding author:}

Brenton Prosser, Australian National University, Hayden Allen Building, Acton, Australian Capital Territory, 0200 Australia.

Email: Brenton.Prosser@anu.edu.au 
is associated with hyperactive behaviour, a difficulty in forming relationships, poor social skills, low school performance and lower school retention. While there remains ongoing debate about the reality and social construction of this disorder, as a category, ADHD has real social impact.

The number of young people diagnosed and treated with psychostimulants for ADHD has grown rapidly in the western world over the last two decades. Between 1994 and 2003, the use of psychostimulants to treat ADHD grew by 274 percent worldwide (Scheffler et al., 2007). Between 1994 and 2000, psychostimulant treatment of ADHD grew by 12 percent per year in ten western nations (Berbatis et al., 2002). International estimates of levels of diagnosis vary between 4 and 7 percent of children (Prosser and Reid, 2009). Diagnosis of ADHD in many western nations is through diagnostic criteria in the DSM, with Australia mirroring North American trends in diagnosis and drug treatment (Berbatis et al., 2002). Until recently, European nations had lower levels of drug treatment; however, there is evidence of this gap closing (Bailey, 2010; Lecendreux et al. 2011). Hence it would seem that ADHD, once diagnosed mostly among white North American young males, is reaching across international boundaries.

There is an overwhelming body of clinical literature considering ADHD, not surprisingly the focus of these papers has been the use, prevalence and trends associated with psychostimulant treatment. Little has been published in the social sciences. Where there has been a growing presence, however, has been in criminological studies. For instance, North American longitudinal studies have found that ADHD is a genetically inherited condition, which if untreated will dramatically increase the incidence of risk-taking behaviour, dangerous driving, substance misuse, depression, criminality and suicide (Barkley, 1998). Also within the United States, a 30-year study found that hyperactive boys had higher rates of arrests, convictions and incarcerations as they entered adulthood (Satterfield and Schell, 1997), while a review of 48 American studies found strong links between ADHD diagnostic measures and delinquent or criminal behaviour (Pratt et al., 2002). Other American studies have also demonstrated a link between ADHD and criminal activity (Barkley et al., 2004; Gunter et al., 2006; Rabiner et al., 2005). Within Europe, long-term studies have linked ADHD to delinquency and criminal behaviour (Lay et al., 2005; Sourander et al., 2006), while European studies also indicate higher rates of ADHD among prison populations (Rasmussen et al., 2001; Rosler et al., 2004) and juvenile delinquents (Doreleijers et al., 2000). In Australia, a number of jurisdictional Australian studies have found ADHD prevalence to be higher in juvenile delinquents (Royal Australasian College of Physicians, 2009).

ADHD has had limited consideration in sociology, and has been virtually ignored as a diagnosis with social impact (Rafalovich, 2001). An analysis of international peerreviewed publications in leading sociological journals only found five papers specifically addressing ADHD over the last 19 years (see Table 1). This limited consideration of ADHD through sociological lenses may be due to two factors. First, an acceptance of the psycho-medical discourses that surround the category and assume that ADHD is a physiological and genetic condition may see ADHD deemed to be outside the auspices of sociological research. Alternatively, a rejection of the psycho-medical discourses surrounding ADHD may result in the label being so closely tied to reductionist logics that it would be seen to constrain rigorous sociological research. However, in this article I argue 
Table I. Papers referring to 'ADHD’a in leading sociology journals (1994-2012).

\begin{tabular}{|c|c|c|c|c|c|c|c|}
\hline ERA rank ${ }^{b}$ & Journal & Author (year) & Medicalise & Media & Stigma & Crime & Parenting \\
\hline \multirow[t]{11}{*}{$A^{*}$} & American Journal of & Gou (2008) & & & & & \\
\hline & Sociology & Shostak (2008) & & & & & \\
\hline & American Sociological & Clarke (2003) & & & & & \\
\hline & Review & Duster (2006) & & & & & \\
\hline & & Guo (2008) & & & & & \\
\hline & Annual Review of & Link (200I) & & & & & \\
\hline & Sociology & Jenness (2004) & & & & & \\
\hline & & McCarthy (2008) & & & & & \\
\hline & Body \& Society & Bennett (2007) & & & & & \\
\hline & & Heyes (2009) & & & & & \\
\hline & Sociology & Abraham $(2010)^{c}$ & & & & & \\
\hline \multirow[t]{12}{*}{ A } & $\begin{array}{l}\text { Analyses of Social } \\
\text { Issues }\end{array}$ & Leverson (2007) & & & & & \\
\hline & Gender \& Society & Blum (2004)c & & & & & \\
\hline & & Litt (2004) & & & & & \\
\hline & & Blum (2007) & & & & & \\
\hline & & Scott $(2010)$ & & & & & \\
\hline & $\begin{array}{l}\text { Media, Culture \& } \\
\text { Society }\end{array}$ & Newman (2010) & & & & & \\
\hline & $\begin{array}{l}\text { Science, Technology } \\
\text { \& Human Values }\end{array}$ & Latimer (2006) & & & & & \\
\hline & & Rapp (20II) & & & & & \\
\hline & Social Forces & Schnittner (2009) & & & & & \\
\hline & Social Problems & Conrad $(2000)^{c}$ & & & & & \\
\hline & Sociological Inquiry & Boeri (2006) & & & & & \\
\hline & & $\operatorname{Neff}(2010)$ & & & & & \\
\hline Other & Deviant Behaviour & $\begin{array}{l}\text { Rafalovich }(2001)^{c} \\
\text { Johnson }(2007)^{c}\end{array}$ & & & & & \\
\hline
\end{tabular}

Notes

${ }^{\text {aADHD }}$ was first given this nomenclature in 1994.

'Rankings are drawn from the Australian Research Council, 2010, Excellence in Research for Australia initiative. 'These five papers focus primarily on ADHD; the others only make brief reference to ADHD.

that there remain important questions about ADHD that sociological perspectives can consider which these psycho-medical discourses leave untouched.

For instance, while an emphasis on patients receiving treatment passively in order to fit social expectations within clinical, medical and pharmaceutical perspectives has something in common with the structural functionalist paradigm within sociology, what the latter provides, is scope to consider individual autonomy. Likewise, conflict perspectives emphasise structural influences, but also provide scope to consider acts of resistance - an important insight for ADHD, as opposition to and defiance of authority is typical of those diagnosed as affected by ADHD. Further, ADHD has evolved from a diagnostic term to a popular label, hence there is scope within interactionist perspectives to consider the negotiation of individual agency with social structures in the development of ADHD identities. What such perspectives can offer the social sciences 
(particularly in a context where a criminological emphasis on individual deficit is emerging alongside medicalised views of ADHD), is a more balanced approach to understanding the role of both structure and agency in relation to ADHD.

\section{Medicalisation and ADHD}

A leader in sociological consideration of ADHD has been Peter Conrad. His early work traced the social factors behind the growing interest in the hyperactive label in the United States (Conrad, 1976). More recently, Conrad (2007) noted how the expansion of the diagnostic category of ADHD (with the inclusion of inattentive behaviours) has substantially increased the number of people who could be diagnosed with the disorder, as well as contributing to the growing interest in adult ADHD. Basing his argument on historical analysis, Conrad claims that once a medical means of social control exists then it is only a matter of time before a label emerges to justify its use as treatment for a social problem, and these labels can often expand beyond their original domain to claim other social problems.

More recently, pharmaceuticalisation, as defined by John Abraham (2010), has drawn attention to the process whereby social, behavioural or bodily conditions are treated with drugs. While similar to medicalisation, pharmaceuticalisation moves beyond considerations of the power of medical labels to look at changing patterns in drug treatment. The example used by Abraham to make this case (and to comment on Conrad) is that of ADHD. While Conrad uses the rise in the ADHD label as an example of how behavioural categories are medicalised, Abraham notes that drug use for ADHD did not skyrocket until the late $1980 \mathrm{~s}-20$ years after psychostimulant treatment became available. Hence he responds to Conrad's claim that a label is the inevitable result of access to medical social control by arguing that, although a rise in drug treatment may result from expanded diagnosis, most of this rise derives from a more recent preference for pharmaceutical treatment. Essentially, Abraham argues that the growth in ADHD is an example of a growing acceptance of drug-taking, rather than a growth in medical dominance, in western societies.

What this past work has shared is an emphasis on the treatment of ADHD by medical treatment of ADHD as an illustrative example, but what it has overlooked is the emerging place of ADHD in western culture in its own right. Rafalovich (2001) notes this trend and argues that ADHD could benefit from broader sociological examination. For instance, while Conrad (2007) noted the importance of the media in the promotion of labelling and medical interventions by the pharmaceutical industry, his consideration of medicalisation did not explore the influence of different media contexts outside the United States (Abraham, 2010) nor the interest of the media in this controversial label in itself. To assume that current affairs media or the writers of popular music/television are merely advocates driven by the agenda of the medical profession and pharmaceutical industry underplays the internal logics of these fields and the resistance or appropriation that occurs within them. So, while the medicalisation thesis can explain how the diagnostic category came to claim 'inattention' (Conrad, 2007), it does not consider what Newman (2010) explains as the popular acceptance of a link between short attention span and low intelligence in popular culture (which may have also contributed to the rise 
of the label). Further, while medicalisation can explain the expansion of diagnostic categories in the DSM (most of which are little known to those outside of psycho-medical discourses), it does not fully explain how some categories (such as Alzheimer's, anorexia and ADHD) have achieved a popular prominence beyond their specific medical nomenclature. Hence, while the medicalisation thesis can explain how the medical profession lends authority to the concept, it does not adequately address the place of the label in popular culture or the ways that agents view, experience and respond differently to the label (see Danforth and Navarro, 2001; Singh, 2002).

There is another limitation associated with a medicalisation perspective, namely that it does little to challenge the taken-for-granted (mis)conceptions about ADHD. For instance, the popular view that ADHD is caused by bad parenting is mirrored in medicalisation views of parents uncritically accepting the authority of the medical professional to control their child and alleviate their feelings of guilt. However, some young people are labelled without a medical professional ever being consulted (Diller, 1998) and research shows that families do not quickly or easily embrace the label or medication (Taylor et al., 2006). Another popular view is that ADHD is just another name for naughty children, a view echoed in medicalisation views that as social expectations around good behaviour converge, labels emerge to claim the newly identified outliers, and then medical technology is developed to treat them. However, this does not explain why some non-conforming children are not labelled and treated, nor does it explain international variations in medical treatment by gender, ethnicity and class. In essence, the medicalisation perspective is problematic because it gives theoretical robes to barely concealed popular misconceptions about ADHD, and potentially leaves them immune from sociological consideration.

Finally, the medicalisation perspective has come under scrutiny because of its association with the concept of medical dominance. 'Medical dominance' is a term used to describe the power of the medical profession to control its work, to shape health policy and reify the knowledge that it creates about individuals (Germov, 2009; Willis, 2006). This concept was highly influential around the time that ADHD was first used as an example of the medicalisation of society (Conrad, 1976). However, since that time it has been argued that the medical role and authority is under challenge by other health professionals (Germov, 2009), that medicine and psychiatry never had complete control over patients and resources (Roach Anleu, 2009) and that the medical profession is not a unified force in society (Willis, 2006). The ongoing controversy around ADHD in leading medical journals (such as the Australian and New Zealand Journal of Psychiatry) and the withdrawal of the latest Australian national guidelines on ADHD - due to concern about links between a key contributor and the pharmaceutical industry (Sikora, 2009) both suggest limits to an assumed medical dominance over ADHD. When considering ADHD in the Australian context, it should also be noted that the medicalisation perspective was developed in the United States, where historically there have been stronger links between the pharmaceutical industry, private health provision and ADHD support groups. Further, critiques of medicalisation and medical dominance also point to the rapid growth in sources of information from outside the scope of medicine that challenge its authority (Broom, 2005). This is highlighted in the case of ADHD by the immense body of information available on the internet and the prominence of the label within popular culture (see Prosser, 2006). 


\section{ADHD, popular culture and crime}

Importantly, in Australian and American popular culture, the label ADHD has come to be associated with any 'bad behaviour' and no longer needs to have been diagnosed or treated with drugs for the label to be used. The label is now referred to regularly in television and popular music, as well as having a prominent presence in entertainment and news media. Such 'black or white' controversies around ADHD perpetuate a debate about it as a myth (Laurence and McCallum, 1998) which can result in cycles of blame rather than fewer misconceptions about it among families and the community (Singh, 2004; Lloyd et al., 2006; Prosser, 2010a).

Further, these popular representations that present children out of control, fears about drug use, allegations of poor parenting and links with crime are highly influential on parental and community views (see Prosser, 2006a). Such powerful everyday discourses (Danforth and Navarro, 2001) are evident in Australian talkback radio (Prosser, 2010a), the internet (Prosser, 2006a), current affairs television formats (Prosser, 2006b) and in newspapers (Norris and Lloyd, 2000). What this highlights is the importance of popular culture as a source of knowledge about ADHD that is outside the auspices of the medical profession and counteracts the sole influence of medicalisation.

To illustrate the importance of an examination of ADHD and popular influences, a consideration of its supposed association with youth offending, substance misuse and crime can yield insights. As noted previously, clinical, psychiatric and criminological research has reported that there is a correlation between ADHD and delinquency/criminality. However, a sociological consideration highlights a number of reasons to exercise caution in accepting these findings at face value. First, there is no physiological test to establish the presence of ADHD (Abraham, 2010); rather, diagnosis in the DSM is made by subjective assessments of impairment against a series of behavioural descriptors. Hence there is no discrete condition on which to build a case for causality. Second, the descriptors that are the basis for diagnosis span hyperactive, inattentive and combined subtypes (American Psychiatric Association, 2000), which results in a vast array of possible combinations of behaviour that can secure an ADHD diagnosis. Hence, the diversity of behaviour that falls under the same diagnosis - ADHD - is so broad that linking the whole category to delinquency/crime offers little advantage as it is nearly impossible to identify and control each of the variables within the subtype to see which may have such links. Further, links between diagnostic terms and research categories rarely align. Even within the research previously cited, the categories of examination used vary between hyperactivity, inattention, attention deficit and ADHD. It must be stressed that the presence of inattention does not make a child delinquent and the presence of hyperactivity does not turn a child into a criminal. What is occurring here is not the growing identification of a causal link between a more refined diagnosis of a physical condition and criminal predispositions; rather it is criminological research being influenced by psycho-medical discourses (Roach Anleu, 2009) and absorbing populist assumptions about ADHD, both of which overlook the changing relationship between social norms, social order and social control. Hence, a key insight from sociological perspectives is that any popular notion that ADHD is a pre-determinant of delinquency and crime should be viewed with scepticism. 


\section{A sociological understanding of ADHD}

The potential contribution of classical sociology to understandings of ADHD was first raised by Ideus (1994). She explored ADHD as an ethnocentric and de-contextualised phenomenon that needed to be considered in the light of the American cultural foundations from which it emerged. She argued that the scholars and professionals of any country that wanted to embrace ADHD must first deal with the cultural considerations that have been rendered invisible in the North American context. To assist in a stronger cultural understanding of ADHD, she argued for greater attention to what insights classical sociological analysis might offer. This observation is particularly pertinent for examinations of ADHD in Australia, where there are distinct differences from the United States in terms of policy arrangements (Prosser et al., 2002) and cultural identity (Prosser, 2006a). When considering ADHD as an aspect of popular culture, it is important to note recent post-structural analysis of the ADHD diagnostic criteria (Bailey, 2010), while similar analyses of ADHD as a product of competing discourses within schooling are also an important contribution to the field (Danforth and Navarro, 2001; Graham, 2007). However, in this article I have chosen to respond to the call made by Ideus (1994) to draw on resources from classical sociology and, given my focus on the growing association of ADHD with delinquency and crime, I have particularly chosen to draw on conceptual resources from within the sociology of deviance.

Deviance is a flexible concept that at its broadest can be taken to be any behaviour that violates people's expectations or any behaviour that is subject to regulation or control. It is important to note the distinction between 'deviance' as the study of variations from behavioural norms (such as ADHD) and 'deviant' as a stigmatising label. The study of deviance allows for consideration of behaviour both within and outside of recognised 'deviant' categories, in contrast to criminology, which tends to emphasise the processes of criminality and recidivism. While there remains a debate about the 'death' of the deviance category (Bendle, 1999; Best, 2004; Sumner, 1994), my position is to affirm the relevance of deviance as a distinct sub-field of sociology and as a useful analytical concept (Roach Anleu, 2006), while pointing to the fact that deviance is still being taught and widely used within Australian schools of sociology. To demonstrate this position, I have intentionally looked at the deviance category because of its illustrative capacity and potential to draw from across classical sociological paradigms.

To frame the considerations that are to follow, it is important to give a brief overview of each of the classical perspectives, their connections and their respective positions on the relative role of structure and agency in relation to ADHD. While biomedical and criminological approaches share an emphasis on making the agent fit social structures, the classical sociological perspectives allow greater consideration of individual agency. Structural functionalist perspectives consider the strain experienced by individuals and families when social demands and individual capacity are mismatched. Such perspectives can be helpful for professionals who want to help young people to function in social environments without defaulting to drug or punishment options. Conflict approaches identify the potential for individuals and families to resist ideas of normal behaviour in social systems as defined by power groups. Taking such a socially critical view on policy and resources can help professionals provide opportunities to reduce the institutional 
marginalisation of young people with ADHD. Further, a consideration of identity development as a dialectical process of interaction between individuals and social constructions can open up new opportunities to see the creation, recreation, appropriation and evolution of ADHD identities among Australian youth.

\section{Structural functionalism and ADHD}

Based on the idea that society is like a well-oiled machine, structural functionalism focuses on the processes by which social cohesion and order is maintained through the imposition of a collective value system. Hence, it views deviance as all behaviour that breaks the social norms that have been produced through the consensus of society. This perspective not only sees deviant behaviour as inevitable in any given society, it also argues that social structures actually encourage some people to become deviant. This is because deviance has the important function of fostering new ideas and change, as well as uniting the collective against deviant acts, hence strengthening the social glue within society. From this perspective, it could be argued that diagnosing and treating ADHD is necessary for the well-being of individual, family and society. In this view it could be argued that the rise in ADHD diagnosis is due to a lack of time for the human gene pool to evolve in response to the significant social, economic and technological change in the western world over the last 30 years (deGrandpre, 2000; Diller 1998). In this view, society's demands for conformity are legitimate and compelling, while it is the role of the individual to conform. Such views have been influential among professionals within the North American context (Danforth and Navarro, 2001; Ideus, 1994).

Highly influential within structural functionalist considerations of deviance has been the concept of anomie. Emile Durkheim (2002) argued that rapid social changes could disrupt traditional social norms and result in a state of normlessness (or anomie). This situation, where traditionally accepted norms are incomprehensible in the context of people's lives, leaves them without a moral compass and put them at risk of deviance, criminality and potentially suicide. Proponents of this view might ask if the greater popular interest in ADHD may be in some part a result of a broader sense of anomie around contemporary behavioural norms. A useful approach from within this perspective is to consider links between ADHD, delinquency and crime through the concept of structural strain. Robert Merton's (1938) anomic structural strain proposed that modern society was not so much experiencing a lack of norms, as that existing traditional norms were no longer relevant. Merton explained that when there is a gap between culturally approved goals and the means available to attain them then there are a number of responses by humans to this strain, with innovation or rebellion (i.e. deviance) being possible outcomes. A recent example of the application of strain theory in relation to ADHD can be found in an American study by Johnson and Kercher (2007).

Support to address such strain can take the form of 'goodness of fit' approaches to help youth to meet changing school and social demands (Reid et al., 1998a). For instance, in a previous role running respite programmes for children with challenging behaviours (Prosser, 2006b), we adopted a functionalist approach to restructure programmes to teach social skills and support youth to function in social environments without relying on drug treatment. What this involved was an assessment of the temporal, spatial and 
activity-related demands to see which caused the children most difficulty and then the redesign of environments, teaching related skills and scaffolding their re-entry into demanding school and everyday situations. These changes were as simple as not asking them to read in front of others or not to do quieter activities immediately after vigorous activity outside. They were also as complex as taking responsibility for negotiating group expectations and taking on short periods of group leadership. While biomedical approaches focus primarily on short-term compliance, they leave unanswered the questions of what happens when the influence of medication subsides or how skills are acquired to ameliorate the impact of ADHD behaviours in adult life. I would argue that a structural functionalist perspective can help professionals working with ADHD to move past a short-term drug-or-punish approach, while it allows social scientists to use ADHD as a lens through which to consider the embodiment of emerging social priorities in a context of rapidly changing behavioural norms (such as those relating to masculinity).

\section{Interactionism and $A D H D$}

Interactionist perspectives stress that human action emerges from the meaning-making that occurs in the interaction between individual agency and social structure. A great deal of the work that is identified as interactionist builds on that of Mead (1974) and Blumer (1971), which considers the role of the 'self' in the social construction of identity. However, from an interactionist perspective, the central areas for inquiry in relation to ADHD are the ongoing lack of consensus around the definition of the disorder, the process by which an ADHD identity is socially constructed, and the influence of changing cultural priorities in redefining human diversity as disorder. Ideus (1994) noted that, from an interactionist perspective, ADHD might be seen as the result of a process whereby particular individual traits or behaviours, which are not in themselves harmful, are deemed abnormal or undesirable through social interaction in particular cultural contexts. Also useful in this approach is Goffman's (1974) work on the production of the self and the role of the self in experiencing stigma, which could aid consideration of the impact of the ADHD label on the actions and perceptions of individuals. As Link and Phelan (2001) observe, the role of the social in the selection of certain human differences for stigmatisation is too often overlooked, with deficit labels such as ADHD being an example of how changing contexts are vital in the emergence of 'taken-for-granted' labels in common parlance.

Specifically in relation to the sociology of deviance, Becker (1963) identified the role of deviant labels through his articulation of the Labeling Perspective. In short, Becker's contribution was to shift the focus of considerations of deviance from the labelled individual to the labeller. He argued that social groups create deviance by making the rules and then labelling those who break them as 'outsiders'. Hence deviance is not related to the act a person commits but to the reaction of those around them, with the deviant being one who has accepted the label into their identity. It was using this approach that Peter Conrad subsequently made his important contribution through the concept of medicalisation (although his work focused on the views of parents and professionals about the ADHD label and did not examine the perspectives of those who 
were labelled). It is important to reiterate here that my argument is not that we should disregard medicalisation altogether; it remains a vital tool in understanding a range of structural influences on ADHD. However, as I have discussed above, additional perspectives from within the sociology of deviance can supplement some of its limitations in understanding the relative role of agency and unpacking some of the taken-forgranted popular ADHD myths.

Previously, I have used interactionist approaches to explore the impact of the ADHD label on adolescent identity development (see Prosser, 2006a, 2006b, 2008), and particularly the way that youth and families come to adopt, refine and use ADHD labels (Norris and Lloyd, 2000; Singh, 2002, 2004; Taylor et al., 2006). A common theme within my past work with adolescents in schools (who had been labelled with the disorder) was their description of themselves having 'mild ADHD' (Prosser, 2006a). From a biomedical perspective, such a claim makes no sense - either one has ADHD or one does not. However, from an interactionist perspective 'mild ADHD' can be seen as an identity that has been created by actors to negotiate contradictory demands of structure and agency. For instance, as these young people voiced strong opposition to what they saw as highly influential (mis)representations of ADHD and stereotypes in the media, they also maintained that they encountered difficulties at school for which they needed support. They were not willing to incorporate the ADHD label into their identity in the form it was provided to them, but neither were they in a position where they were able to reject completely a label that was endorsed by their family and was seen to assist them in practical ways. The contribution of an interactionist perspective is to emphasise the constant renegotiation of agency and structure in maintaining an ADHD identity as one of many other identities. For families, teachers and health professionals, this perspective provides deeper insight into the experience of living with ADHD, which can contribute to greater compassion and understanding. It also provides social scientists with the potential to consider the evolving nature of identities and explore individual accounts of either 'growing out of' or embracing the ADHD label as adults.

An interactionist perspective on the link between ADHD, delinquency and crime lends itself to considering this link using the concept of moral panic. Cohen (1980) defines moral panic as a situation where a group of persons become defined in a stereotypical fashion as a threat to society, usually based on the concerns of politicians, the police and reports in the media. According to this view, the media portray potential 'crime waves' caused by 'folk devils' by exaggerating the numbers of people and the degree of the threat to society. It is in this context that we can see that representations of ADHD in Australia have many of the characteristics of a moral panic. However, in the case of ADHD, there are two important distinctions. First, ADHD is caught between conflicting concerns about 'the youth crime problem' and prescribing amphetamines (that also have a reputation as illicit drugs) to youth as a means to 'fix' the problem. Second, the reporting of problem behaviours does not emerge from the police (in line with the classic definition of moral panic); rather, reports emerge from new 'sickness brokers' (Phillips, 2006) who are interested in maintaining social order (such as teachers, social workers and medical professionals). Hence, the interactionist perspective would contend that what may be behind the growing interest in the ADHD label in Australian 
culture in recent years might not be a growing number of youth participating in defiant, delinquent and illegal behaviour; rather it may be a response to a supposed threat from youth to social order.

\section{$A D H D$, conflict and resources}

The conflict perspective views society as a maelstrom of conflicting interests, while social order is the product of the exercise of power by elites to ensure an ability to control production and profit in capitalist society. Built on the materialist view of history presented by Marx (1958), conflict theories are about considering the unequal distribution of power and, when applied to the concept of deviance, focus on rule-breaking as a response to this inequality. From a conflict perspective, deviance and crime only emerge to claim acts that are a direct threat to the foundations of capitalism. The main contribution of these approaches to deviance has been to understand how economic and ideological power shapes what is considered as deviant. Ideus (1994) explained that views from within this theoretical perspective would see ADHD as an ideological ploy to oppress individual interests in the face of social machinery that seeks to maximise economic profit. This manipulation may take one of the forms articulated by Quinney (1970), where interest groups lobby to affect public policy, resources and the enforcement of social control, or where ruling groups become central in defining what it is to be criminal (Quinney, 1977). From a conflict perspective, consideration is needed of both the role of the ADHD label for parents and advocates lobbying for resources in western societies, and the role of powerful economic groups in defining what ADHD is and how it is to be controlled.

The links between pharmaceutical companies, advocacy groups and medical practitioners has been explored in depth elsewhere (Abraham, 2010; Lloyd et al., 2006; Timmi, 2005). However, what also requires analysis from a conflict perspective is the role of the label in competing for resources and support from social welfare institutions. Emerging in a post-welfare context that is reducing real term funding and emphasising devolution of responsibility to the individual or family (Adams, 2008; Timmi, 2005), ADHD has become a contested category. In the face of this, Australian politicians and policy-makers have been careful to avoid specific policy action because of its potential resource implications (Prosser, 2006a). Despite this, errant perceptions that the medical label provides additional welfare support persist, which drive lobbying and advocacy efforts (Reid et al., 1994; Roach Anleu, 2009). That said, it might also be a realisation of the limitations of the label as a tool for lobbying that have resulted in recent media reports that ADHD is being replaced by autism as the most sought-after diagnosis in Australia (Hansen, 2010).

Currently in Australia, there are no specific policies or additional resources (other than medication) allocated with ADHD diagnosis. Government support for free medical consultations (through the Australian Medicare Benefits Scheme) and subsidies for ADHD medications (through the Australian Pharmaceutical Benefits Scheme) is seen to result in the medicalisation of ADHD by default (Prosser et al., 2002). Such a view draws on traditional approaches to public policy, which emphasise the role of governments, ministers and departments, and have resulted in a public policy deadlock 
surrounding ADHD. In this view, it is the cracks between federal and jurisdictional policy that children fall through to land in the hands of the medical profession and receive an ADHD diagnosis. However, such a view overlooks much of the complexity of how individuals, families and interest groups in communities are gaining knowledge, accessing resources and responding to ADHD beyond the stalemate in public policy on ADHD.

For instance, such views do not explain why rates of ADHD diagnosis and medical treatment in Australia vary by gender, ethnicity and socio-economic background (Prosser, 2006a). Due to their focus on policy-makers, neither can they explore the extent to which different professional and other stakeholders are reinforcing or resisting ADHD diagnosis and medical treatment. However, the conflict tradition (with its focus on multiple competing interests contesting over resources) has developed new public policy perspectives, such as new or network governance (Bell and Hindmoor, 2009), which can offer a way past the ADHD public policy stasis. Applying such a sociological view to ADHD opens up new avenues to see it as a vibrant and active space, in which a range of actors are involved in defining categories, creating knowledge, forming responses and lobbying for resources (beyond just the medical). While yet to be explored thoroughly with ADHD, such conceptual resources could end the policy stagnation with regard to ADHD and could enable consideration of the mix of supports and responses being devised by communities around ADHD (which are overlooked by solely medicalised perspectives).

While a correlation between regions that are lower on the socio-economic scale and higher psychostimulant treatment has been identified in Australia (Prosser and Reid, 2009), this is not a situation directly replicated in the United States. Notably in the US, levels of diagnosis and treatment are lower among Afro-American and Latino communities (Bailey et al., 2010; Eiraldi and Diaz, 2010). Largely this is due to differing access to medical services. As mentioned above, in Australia, families receive free medical consultations through Medicare and can access highly subsidised medication through the Pharmaceutical Benefits Scheme. Meanwhile in the United States, lower levels of private insurance and inconsistent use of Medicaid by lower socio-economic groups result in lower levels of access to ADHD diagnosis (Newacheck et al., 1996; Pastor and Reuben, 2008; Zito et al., 1998). Further complicating this situation is disregard of cultural differences in rating scales (Reid et al., 1998b) which may impact on relative diagnosis, while negative associations with psychostimulants among Afro-American and Latino communities may contribute to resistant parental attitudes toward medication (McLeod et al., 2008; Pham et al., 2010). What a comparison of these differing contexts illustrates is the need for social scientists to conduct more detailed examination of the role of socio-economic, public policy and cultural influences in the diagnosis and medical treatment of ADHD in different nations.

\section{Concluding remarks}

This article draws on a range of concepts from within classical sociology and the sociology of deviance to explore the reported link between ADHD diagnosis, the ADHD label and delinquency/crime. It has argued that any proposed link should be viewed cautiously 
and more as a product of social forces than any inherent quality within the individual. In doing so, the article has argued that more rigorous sociological conceptualisations of ADHD are needed than those provided through the existing body of writing in medical, psychiatric and criminological disciplines.

While it is beyond the scope of this article to review all the potential conceptual contributions available from within classical and post-structural sociology, the range presented above highlights at least three potential avenues for future research. First, why is it that Australia has so closely mirrored North American trends in ADHD diagnosis and medication use? If this is (as it is often claimed) a product of the medicalisation of society, then examination is needed of the reasons why these two nations adopted ADHD so swiftly, as well as exploration of cultural and institutional factors that contribute to different manifestations of ADHD in each context. Second, it is often (darkly) observed among professionals working with ADHD that a child 'gets ADHD from their mother's friend watching television'. More work is needed to build on previous discussions of the relationship between ADHD, the media and popular culture. Further, and of particular interest to the author, is that it is often observed that levels of ADHD diagnosis and medical treatment are lower among indigenous Australian children or children with Asian Australian parents. Further research is needed to assess whether such observations are empirically supported and the extent to which they align with the experience of Latino and African American families in the United States. Finally, more research is needed that is cognisant of the potential for criminological and medicalisation perspectives to reinforce populist myths about ADHD and underplay the relative role of agency in our understandings of ADHD. While not dismissing the influence of social structures, such research would address the strange oversight within current social science perspectives that present a group of young people typified by their defiance of social norms as passive receptors of the influences of medical dominance and medicalisation in western society. With such matters in mind, it is clear that ADHD could provide a lens through which to consider a range of changes and challenges in contemporary Australian society. Hence, this article not only seeks to enhance understanding of the place of this prominent disorder in Australia, but also to encourage the potential development of sociologically informed conceptualisations that move beyond the limitations of the existing medically dominated views of the ADHD label.

\section{Funding}

This research received no specific grant from any funding agency in the public, commercial, or not-for-profit sectors.

\section{Note}

1. The author acknowledges the release of the new DSM-V in mid 2013 with its refinements to diagnostic criteria for $\mathrm{ADHD}$, but notes that the underlying definition of the disorder has not changed since the release of the DSM-IV.

\section{References}

Abraham, J. (2010) 'Pharmaceuticalization of Society in Context: Theoretical, Empirical and health dimensions', Sociology 44(4): 603-22. 
Adams, P. (2008) 'Positioning Behaviour: Attention Deficit/Hyperactivity Disorder (ADHD) in the Post-welfare Education Era', International Journal of Inclusive Education 12(2): $113-25$.

American Psychiatric Association (2000) Diagnostic and Statistical Manual of Mental Disorders $(D S M-I V-R)$ (4th revised edn). Washington, DC: American Psychiatric Association.

Bailey, R.K., S. Ali, S. Jabeen, H. Akpudo, J.U. Avenido, T. Bailey et al. (2010) 'Attentiondeficit /Hyperactivity Disorder in African American Youth', Current Psychiatry Reports 12(5): 396-402.

Bailey, S. (2010) 'The DSM and the Dangerous School Child', International Journal of Inclusive Education 14(6): 581-92.

Barkley, R.A. (1998) Attention-Deficit Hyperactivity Disorder: A Handbook for Diagnosis and Treatment (2nd edn). New York: Guilford Press.

Barkley, R.A., M. Fischer, L. Smallish and K. Fletcher (2004) 'Young Adult Follow-up Of Hyperactive Children: Antisocial Activities and Drug Use', Journal of Child Psychology and Psychiatry 45(2): 195-211.

Becker, H.S. (1963) Outsiders: Studies in the Sociology of Deviance. New York: Free Press.

Bell, S. and A. Hindmoor (2009) Rethinking Governance. Cambridge: Cambridge University Press.

Bendle, M. (1999) 'The Death of the Sociology of Deviance', Journal of Sociology 35(1): $42-58$.

Berbatis, C.G., V.B. Sunderland and M. Bulsara (2002) 'Licit Psychostimulant Consumption in Australia, 1984-2000: International and Jurisdictional Comparisons', Medical Journal of Australia 177(10): 539-43.

Best, J. (2004) Deviance: Career of a Concept. London: Wadsworth.

Blumer, H. (ed.) (1971) Sociological Implications of the Thought of G.H. Mead. London: Routledge \& Kegan Paul.

Broom, A. (2005) 'Medical Specialists' Accounts of the Impact of the Internet on the Doctor/ Patient Relationship', Health 9(3): 319-38.

Cohen, S. (1980) Folk Devils and Moral Panics: The Creation of Mods and Rockers. Oxford: Basil Blackwell.

Conrad, P. (1976) Identifying Hyperactive Children: The Medicalization of Deviant Behavior. USA: D.C. Heath and Co.

Conrad, P. (2007) 'From Hyperactive Children to Adult ADHD', pp. 46-69 in The Medicalization of Society. Baltimore, MD: Johns Hopkins University Press.

Danforth, S. and V. Navarro (2001) 'Hyper Talk: Sampling the Social Construction of ADHD in Everyday Language', Anthropology and Education Quarterly 32(2): 167-90.

deGrandpre, R. (2000) Ritalin Nation. New York: Norton.

Diller, L.H. (1998) Running on Ritalin: A Physician Reflects on Children, Society and Performance in a Pill. New York: Bantam Books.

Doreleijers, T., F. Moser, P. Thijs, H. van Engeland and F. Beyaert (2000) 'Forensic Assessment of Juvenile Delinquents: Prevalence of Psychopathology and Decision-making at Court in the Netherlands', Journal of Adolescence 23(3): 263-75.

Durkheim, E. (2002) Suicide: A Study in Sociology. Abingdon: Routledge.

Eiraldi, R. and Y. Diaz (2010) 'Use of Treatment Services for Attention-Deficit/Hyperactivity Disorder in Latino Children', Current Psychiatry Reports 12(5): 403-8.

Germov, J. (2009) 'Challenges to Medical Dominance', pp. 392-415 in J. Germov (ed.) Second Opinion: An Introduction to Health Sociology (4th edn). South Melbourne: Oxford University Press.

Goffman, E. (1974) Stigma. Harmondsworth: Penguin. 
Graham, L. (2007) 'From ABCs to ADHD: The Role of Schooling in the Construction of Behaviour Disorder and Production of Disorderly Subjects', International Journal of Inclusive Education 12(1): 7-33.

Gunter, T., S. Arndt, K. Riggins-Caspers, G. Wenman and R. Cadoret (2006) 'Adult Outcomes of Attention Deficit Hyperactivity Disorder and Conduct Disorder: Are the Risks Independent or Additive?', Annuals of Clinical Psychiatry 18(4): 233-7.

Hansen, J. (2010) 'Disorder in the Classroom on the Rise', The Weekend Australian 18-19 September: 5 .

Ideus, K. (1994) 'Cultural Foundations of ADHD: A Sociological Analysis', Therapeutic Care and Education 3(2): 173-93.

Johnson, M. and G. Kercher (2007) 'ADHD, Strain, and Criminal Behavior: A Test of General Strain Theory', Deviant Behavior 28(2): 131-52.

Laurence, J. and D. McCallum (1998) 'The Myth or Reality of Attention Deficit Disorder', Discourse 19(2): 183-200.

Lay, B., W. Ihle, G. Esser and M. Schmidt (2005) 'Juvenile-episodic, Continued or Adult-onset Delinquency? Risk Conditions Analysed in a Cohort of Children Followed Up to the Age of 25 Years', European Journal of Criminology 2(1): 39-66.

Lecendreux, M., E. Konofal and S.V. Faraone (2011) 'Prevalence of Attention Deficit Hyperactivity Disorder and Associated Features Among Children in France', Journal of Attention Disorder 15(6): 515-24.

Link, B. and J. Phelan (2001) 'Conceptualizing Stigma', Annual Review of Sociology 27(1): 363-85.

Lloyd, G. (2006) 'Conclusion: Supporting Children in School', in G. Lloyd, J. Stead and D. Cohen (eds) Critical New Perspectives on ADHD. New York: Routledge.

Lloyd, G. J. Stead and D. Cohen (eds) Critical New Perspectives on ADHD. New York: Routledge. Marx, K. (1958) Selected Works. Moscow: Progress Publishers.

McLeod, J.D., D.L. Fettes, P.S. Jensen, B.A. Pescosoldio and J.K. Martin (2007) 'Public Knowledge, Beliefs, and Treatment Preferences Concerning Attention Deficit Hyperactivity Disorder', Psychiatric Services 58(5): 626-31.

Mead, G.H. (1974) Mind, Self and Society. Chicago: University of Chicago Press.

Merton, R.K. (1938) 'Social Structure and Anomie', American Sociological Review 3(5): 672-83.

Newacheck, P.W., D.C. Hughes and J.J. Stoddard (1996) 'Children's Access to Primary Care: Differences by Race, Income, and Insurance Status', Pediatrics 97(1): 26-32.

Newman, M.Z. (2010) 'New Media, Young Audiences and Discourses of Attention: From Sesame Street to "snack culture", Media, Culture \& Society 32(4): 581-96.

Norris, C. and G. Lloyd (2000) 'Parents, Professionals and ADHD - What the Papers Say', European Journal of Special Needs Education 15(2): 123-37.

Pastor, P.N. and C.A. Reuben (2008) 'Diagnosed Attention Deficit Hyperactivity Disorder and Learning Disability: United States, 2004-2006', National Center for Health Statistics. Vital Health Statistics 10(206): 237.

Pham, A.V., J.S. Carlson and J.F. Kosciulek (2009) 'Ethnic Difference in Parental Beliefs of Attention-Deficit/Hyperactivity Disorder and Treatment', Journal of Attention Disorders 13(6): 584-91.

Phillips, C. (2006) 'Medicine Goes to School: Teachers as Sickness Brokers for ADHD'. PLoS Medicine 3(4). URL (consulted 11 November 2011): http://www.plosmedicine.org/article/ info\%3Adoi\%2F10.1371\%2Fjournal.pmed.0030182

Pratt, T., F. Cullen, K. Blevins, L. Daigle and J. Unnever (2002) 'The Relationship of Attention Deficit Hyperactivity Disorder to Crime and Delinquency: A Meta-analysis', International Journal of Police Science Management 4(4): 344-60.

Prosser, B. (2006a) ADHD: Who's Failing Who? Sydney: Finch Publishing. 
Prosser, B. (2006b) Seeing Red: Critical Narrative in ADHD Research. Flaxton: PostPressed.

Prosser, B. (2008) 'Beyond ADHD: A Consideration of Attention Deficit Hyperactivity Disorder and Pedagogy in Australian Schools', International Journal of Inclusive Education 12(1): 81-97.

Prosser, B. (2010a) 'Media and Pedagogical Exchange: Taking ADHD to Radio 2GB', paper presented at the Australian Association for Research in Education Annual Conference, Canberra. URL (consulted 2 September 2013): www.aare.edu.au/09pap/pro091598.pdf

Prosser, B. (2010b) 'Engaging Pedagogies: From Psycho-medical Deficits to "virtual schoolbags", pp. 165-86 in L. Graham (ed.) (De)Constructing ADHD: Critical Guidance for Teachers and Teacher Educators. New York: Peter Lang.

Prosser, B. and R. Reid (2009) 'Changes in Use of Psychostimulant Medication for ADHD in South Australia (1990-2006)', Australian and New Zealand Journal of Psychiatry 43(4): $340-7$.

Prosser, B., R. Reid, R.H. Shute and I. Atkinson (2002) 'Attention Deficit Hyperactivity Disorder: Special Education Policy and Practice in Australia', Australian Journal of Education 46(1): $65-78$.

Quinney, R. (1970) The Social Reality of Crime. Boston: Little, Brown.

Quinney, R. (1977) Class, State and Crime: On the Theory and Practice of Criminal Justice. New York: Longman.

Rabiner, D., J. Coie, S. Miller-Johnson, A. Boykin and J.E. Lochman (2005) 'Predicting the Persistence of Aggressive Offending of African American Males from Adolescence into Young Adulthood: The Importance of Peer Relations, Aggressive Behavior, and ADHD Symptoms', Journal of Emotional and Behavioral Disorders 13(3): 131-40.

Rafalovich, A. (2001) 'The Conceptual History of Attention Deficit Hyperactivity Disorder: Idiocy, Imbecility, Encephalitis and the Child Deviant, 1877-1929', Deviant Behavior 22(1): 93-115.

Rasmussen, K., R. Almik and S. Levander (2001) 'Attention Deficit Hyperactivity Disorder, Reading Disability and Personality Disorders in a Prison Population', Journal of American Academy of Psychiatry and Law 296(2): 186-93.

Reid, R., J.W. Maag and S.F. Vasa (1994). 'Attention Deficit Hyperactivity Disorder as a Disability Category: A Critique', Exceptional Children 60: 198-214.

Reid, R., R. Reason, J. Maag, B. Prosser and C. Xu (1998a) ‘ADHD: A Perspective on Perspectives', Educational and Child Psychology 15(4): 56-67.

Reid, R., G.J. DuPaul, T.J. Power, A.D. Anastopoulos, D. Rogers-Adkinson, M. Noll and C. Ricco (1998b) 'Assessing Culturally Different Students for Attention Deficit Hyperactivity Disorder Using Behavior Rating Scales', Journal of Abnormal Psychology 26(3): 187-98.

Roach Anleu, S.L. (2006) Deviance, Conformity and Control (4th edn). Frenchs Forest, NSW: Pearson Education.

Roach Anleu, S.L. (2009) 'The Medicalisation of Deviance', pp. 242-68 in J. Germov (ed.) Second Opinion: An Introduction to Health Sociology (4th edn). South Melbourne: Oxford University Press.

Rosler, M., W. Retz, P. Retz-Junginger, G. Hengesch, M. Schneider, T. Supprian and J. Thome (2004) 'Prevalence of Attention Deficit-/Hyperactivity Disorder (ADHD) and Comorbid Disorders in Young Male Prison Inmates', European Archives of Psychiatry and Clinical Neuroscience 254(6): 365-71.

Royal Australasian College of Physicians (2009) 'Draft Australian Guidelines on Attention Deficit Hyperactivity Disorder', National Health and Medical Research Council, East Melbourne. 
Satterfield, J. and A. Schell (1997) 'A Prospective Study of Hyperactive Boys with Conduct Problems and Normal Boys: Adolescent and Adult Criminality', Journal of the American Academy of Child and Adolescent Psychiatry 36(12): 1726-35.

Scheffler, R.M., S.P. Hinshaw, S. Modrek and P. Levine (2007) 'The Global Market for ADHD Medications: The United States Is an Outlier among Developed Countries in its High Usage Rates of These Medications among Children', Health Affairs 26(2): 450-7.

Sikora, K. (2009) 'ADHD Guidelines Pulled after Payment Scandal', URL (consulted 2 September 2013): http://www.news.com.au/national-news/adhd-guidelines-pulled-after-payment-scandal/story-e6frfkvr-1225801902002

Singh, I. (2002) 'Bad Boys, Good Mothers, and the“miracle” of Ritalin', Science in Context 15(4): $577-603$.

Singh, I. (2004) 'Doing Their Jobs: Mothering with Ritalin in a Culture of Mother-blame', Social Science \& Medicine 59(6): 1193-205.

Sourander, A., H. Elonheimo, S. Niemela, A.M. Nuutila, H. Helenius, L. Sillanmaki et al. (2006) 'Childhood Predictors of Male Criminality: A Prospective Population-based Follow-up Study from Age 8 to Late Adolescence', Journal of the American Academy of Child and Adolescent Psychiatry 45(5): 578-86.

Sumner, C. (1994) The Sociology of Deviance: An Obituary. Buckingham: Open University Press.

Taylor, M., T. O'Donoghue and S. Houghton (2006) 'To Medicate or Not To Medicate? The Decision-making Process of Western Australian Parents Following their Child's Diagnosis with an Attention Deficit Hyperactivity Disorder', International Journal of Disability, Development and Education 53: 111-28.

Timmi, S. (2005) Naughty Boys: Anti-social Behaviour, ADHD and the Role of Culture. New York: Palgrave Macmillan.

Willis, E. (2006) 'Introduction: Taking Stock of Medical Dominance', Health Sociology Review 15(5): 421-31.

Zito, J.M., D.J. Safer, S. Dosreis and M.A. Riddle (1998) 'Racial Disparity in Psychotropic Medications Prescribed for Youths with Medicaid Insurance in Maryland', Journal of the American Academy of Child and Adolescent Psychiatry 37(2): 179-84.

\section{Author biography}

Brenton Prosser is a former senior lecturer and current adjunct to the School of Sociology at the Australian National University. His research on ADHD reaches back to work with marginalised youth in the 1990s and has focused on the prevalence of ADHD in Australia (along with its professional and policy implications). His book, entitled ADHD: Who's Failing Who?, has sold over 5000 copies internationally. 